\title{
Bacteriological Profile of Ear Infections and Its Antibiotic Susceptibility Pattern in Tertiary Care Hospital Navi Mumbai
}

\author{
Dilshad Arif ${ }^{1}$, Rakesh Kumar Mukhia ${ }^{1}$, Sanjeeva Kumar Goud.T ${ }^{2}$, Junaid \\ Nissar ${ }^{1}$, Rakesh Prasad $\operatorname{shah}^{1}$, Swikriti Singh ${ }^{1}$, Abhay.R.Wagh ${ }^{2}$ \\ Department of Microbiology ${ }^{1}$, Department of Pharmacology ${ }^{2}$ \\ MGM School of Bio- Medical Sciences, Kamothe Navi Mumbai
}

\begin{abstract}
The objective of this study was to know the bacteriological profile and its antibiotic susceptibility pattern of ear infection in patients attending tertiary care hospital \& to study the antimicrobial resistance pattern of the above isolates. Ear swabs were collected \& immediately processed. A total of 80 patients prescription were collected over a period of 7 months comprising 42 males and 38 females. Out of these, Chronic Suppurative Otitis Media (CSOM) was the most common disease \& maximum number of cases was from the age group 21 to 30 years 22 cases (27.5\%). Out of total 80 specimens 11 shows no growth of organism while 69 specimens shows growth of one or two organisms. Out of 69 growths, 58 shows single isolate and 11 shows two isolates. , Pseudomonas, Proteus, Acinetobacter, Klebsiella \& Enterobacter species were the most common Gram-negative bacteria isolated followed by Staphylococcus aureus \& CONS Gram-positive bacteria. The occurrence of gram negative organisms (GNB) was higher than for gram positive (GPC) with GNB 58/91 (63.73\%), GPC 25/91 (27.47\%) and fungi 8/91 (8.80\%). Gram negative bacteria shows $>90 \%$ sensitivity to Ceftazidime, Ciprofloxacin, Lomefloxacin, Gentamicin \& Netilline, >75\% sensitivity to Pefloxacin, Ofloxacin, Cefaperazone \& Amikacin. They are resistance to Amoxyclave, Cefotaxime \& Cefuroxime. Gram positive bacteria shows $>90 \%$ sensitivity to Cephalexin, Linezolid, Gentamicin \& Tetracycline. $>80 \%$ sensitivity Cloxacillin, Cefotaxime, Lincomycin, Co-trimoxazole, Tetracycline \& Amoxyclave.
\end{abstract}

Keywords: Bacteriology, Ear infection, Culture \& sensitivity.

\section{Introduction}

The ear is the organ responsible for hearing and also maintaining balance, it's divided into the outer, middle and inner ear with the outer and middle regions being most susceptible to injury and infections. An ear infection (medically termed Otitis Media) generally refers to an infection of the middle part of the ear that lies behind the eardrum. Ear infections are common in babies and young children, especially those aged six to 18 months. Most children will have an ear infection before the age of five. ${ }^{[1]}$ Chronic Suppurative Otitis Media (CSOM) is chronic inflammation of middle ear, which affects the tympanic membrane, middle ear mucosa and other middle ear structures. Clinically, CSOM presents with ear discharge and conductive deafness. ${ }^{[2]}$ CSOM is one of the most common problems related to ear in developing and developed countries, if left untreated causing more severe loss of hearing. It is characterized by persistent otorrhea for more than 6-12 weeks, through perforated tympanic membrane, usually resulting from previous acute infection. ${ }^{[3]}$ The infection is due to the bacteria coming from nasopharynx via Eustachian tube, and cause inflammation in mucoperiosteum of middle ear cleft, resulting in ear discharge. ${ }^{[4]} \mathrm{CSOM}$ is a global problem and affects all ages but especially prevalent in children younger than 7 years due to horizontal, wider and short Eustachian tube ${ }^{[5]}$ The commonly occurring symptoms are ear discharge, deafness, itching, pain and sometimes fever. If it is left untreated complications like loss of hearing, post aural swelling and post aural sinus may occur. ${ }^{[6]}$

\section{Aims And Objectives}

1) To study the bacteriological profile of ear infection in patients attending tertiary care hospital.

2) To study the antimicrobial sensitivity pattern of the above isolates.

\section{Materials And Method}

Place of study: Department of Microbiology, MGM Medical College \& Hospital at Kamothe Navi Mumbai.

Period of study: July 2013 to January 2014 (7 months).

Type of study: Descriptive study

Number of samples: $\quad 80$

Microbiological Processing of sample: 
Ear swabs were immediately processed. A smear was prepared from the swab and stained by Gram stain. The swabs were cultured on blood agar, Mac Conkey agar and chocolate agar plate. The plates were incubated overnight at $37^{\circ} \mathrm{C}$. Colony count was obtained from blood agar plate. The growth of organism was characterized by colony morphology and Gram's staining from the culture plates. A detailed biochemical testing was performed \& antibiotic sensitivity testing was performed on Mueller-Hinton agar plates by Kirby-Bauer's disc diffusion method using suitable antibiotics as per CLSI (Central Laboratory Standard Institute) guidelines.

\section{Results}

A total of 80 patients prescription were collected over a period of 7 months comprising 42 males and 38 females. Out of these, Chronic Suppurative Otitis Media (CSOM) was the most common disease.

Figure 1: Sex wise distribution of cases.

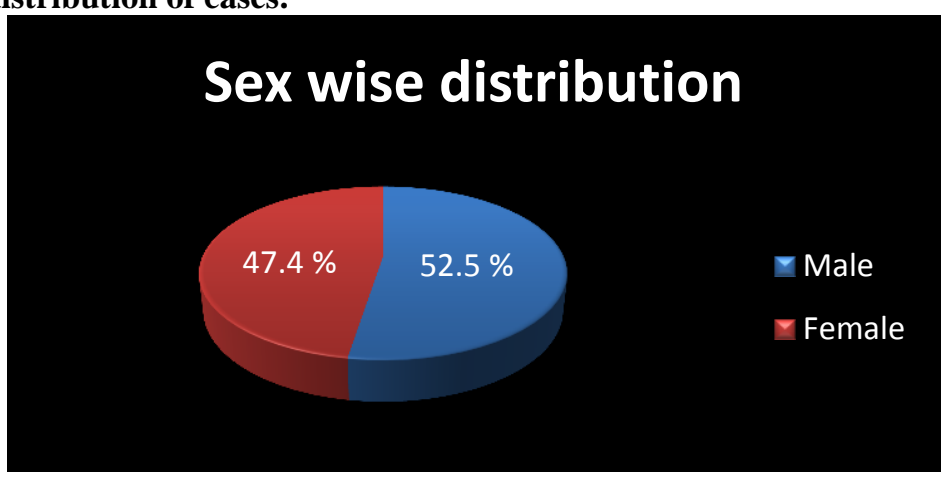

In our study group maximum numbers of cases were from the male group 42 cases $(52.5 \%)$ and females were 38 $(47.4 \%)$.

Table 1: Age wise distribution of cases.

\begin{tabular}{|c|c|c|c|c|}
\hline Age group & Male & Female & Total $(\mathrm{n}=\mathbf{8 0})$ & $\%$ \\
\hline Children < 1 year & 4 & 3 & 7 & 8.75 \\
\hline 11 years to 20 years & 10 & 5 & 15 & 18.75 \\
\hline 21 years to 30 years & 12 & 10 & 22 & 27.5 \\
\hline 31 years to 40 years & 8 & 9 & 17 & 21.25 \\
\hline 41 years to 50 years & 3 & 5 & 8 & 10 \\
\hline 51 years to 60 years & 4 & 3 & 7 & 8.75 \\
\hline$>61$ years & 3 & 1 & 4 & 5 \\
\hline
\end{tabular}

In our study maximum number of cases was from the age group 21 to 30 years 22 cases (27.5\%).

Figure 2: Number of isolates.

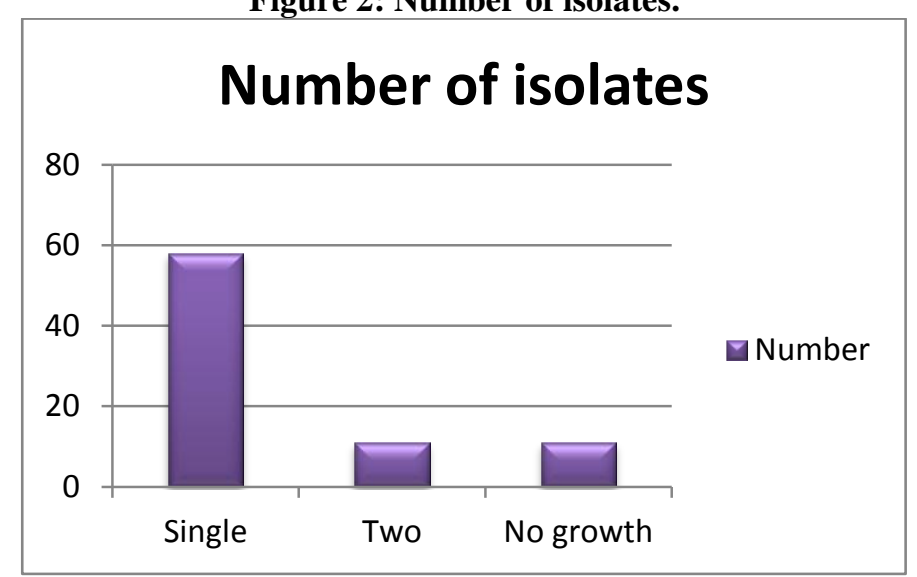

Out of total 80 specimens 11 shows no growth of organism while 69 specimens shows growth of one or two organisms. Out of 69 growths, 58 shows single isolate and 11 shows two isolates.

Table 2: Aerobic bacteria isolated from ear infection.

\begin{tabular}{|c|c|c|c|c|c|}
\hline \multicolumn{2}{|c}{ Organism } & Isolated $(\mathrm{n}=91)$ & $\%$ \\
\hline 1 & Gram Negative bacteria & Pseudomonas spp. & 31 & $\mathbf{3 4 . 0 7}$ \\
\hline
\end{tabular}




\begin{tabular}{|c|c|c|c|c|}
\hline & \multirow{6}{*}{$\begin{array}{c}\mathbf{n}=58 \\
(63.73 \%)\end{array}$} & Proteus spp. & 8 & 8.79 \\
\hline & & Enterobacter spp & 6 & 6.59 \\
\hline & & Acinetobacter spp. & 5 & 5.5 \\
\hline & & Klebsiella spp. & 5 & 5.49 \\
\hline & & E. coli & 1 & 1.09 \\
\hline & & Citrobacter spp. & 2 & 2.2 \\
\hline \multirow[t]{4}{*}{2} & \multirow{4}{*}{$\begin{array}{c}\text { Gram Positive bacteria } \\
\qquad \begin{array}{c}\mathbf{n}=\mathbf{2 5} \\
(27.47 \%)\end{array}\end{array}$} & S. aureus & 16 & 17.59 \\
\hline & & CONS & 7 & 7.7 \\
\hline & & S. pneumoniae & 1 & 1.09 \\
\hline & & S. pyogenes & 1 & 1.09 \\
\hline \multirow[t]{3}{*}{3} & \multirow{3}{*}{$\begin{array}{c}\text { Fungi } \\
\mathbf{n}=\mathbf{8} \\
(8.80 \%)\end{array}$} & Aspergillus niger & 3 & 3.3 \\
\hline & & Penicillium spp. & 2 & 2.2 \\
\hline & & Candida spp. & 3 & 3.3 \\
\hline
\end{tabular}

$\mathrm{n}=$ no of isolates,

The occurrence of gram negative organisms (GNB) was higher than for gram positive (GPC) with GNB 58/91 (63.73\%), GPC 25/91 (27.47\%) and fungi 8/91 (8.80\%). Out of 80 specimens, 11 specimens shows no growth of organism so out of 69 cases which showed growth of total 91 bacteria because of 11 multiple isolate growth pattern. In our study out of 91 bacterial isolated, Pseudomonas, Proteus, Acinetobacter, Klebsiella \& Enterobacter species were the most common Gram-negative bacteria isolated followed by Staphylococcus aureus, CONS Gram-positive bacteria and fungi (Aspergillus, Penicillium \& Candida species).

Table 3: Antibiogram of gram-negative isolates.

\begin{tabular}{|c|c|c|c|c|c|c|c|}
\hline S.N & Antibiotics & $\begin{array}{c}\text { Antibiotics } \\
\text { Symbol }\end{array}$ & $\begin{array}{c}\text { Pseudomonas } \\
\text { spp. }(\mathrm{n}=31) \\
\%\end{array}$ & $\begin{array}{c}\begin{array}{c}\text { Proteus } \\
\text { spp. } \\
(\mathbf{n}=8) \\
\%\end{array} \\
\text { \% }\end{array}$ & $\begin{array}{c}\text { Enterobacter } \\
\text { spp. }(\mathrm{n}=6) \\
\%\end{array}$ & $\begin{array}{c}\text { Acinetobacter } \\
\text { spp. }(\mathbf{n}=5) \\
\%\end{array}$ & $\begin{array}{c}\text { Klebsiella } \\
\text { spp. } \\
(\mathbf{n}=5) \\
\%\end{array}$ \\
\hline 1 & Pefloxacin & $\mathrm{PF}$ & 93.54 & 75 & 83.3 & 80 & 100 \\
\hline 2 & Ofloxacin & $\mathrm{OF}$ & 93.54 & 100 & 66.6 & 80 & 100 \\
\hline 3 & Ciprofloxacin & $\mathrm{RC}$ & 96.8 & 100 & 83.3 & 100 & 100 \\
\hline 4 & Lomefloxacin & LO & 87 & 100 & 50 & 100 & 100 \\
\hline 5 & Cefaperazone & CS & 90 & 87.5 & 66.6 & 100 & 100 \\
\hline 6 & Amikacin & $\mathrm{AK}$ & 90 & 87.5 & 66.6 & 100 & 100 \\
\hline 7 & Gentamicin & G & 96.8 & 100 & 66.6 & 100 & 100 \\
\hline 8 & Netilline & NT & 80 & 100 & 83.3 & 100 & 100 \\
\hline 9 & Cefuroxime & $\mathrm{CU}$ & $\mathrm{R}$ & 87.5 & 66.6 & $\mathrm{R}$ & 60 \\
\hline 10 & Cefotaxime & $\mathrm{CE}$ & $\mathrm{R}$ & 87.5 & 50 & 60 & 80 \\
\hline 11 & Ceftazidime & $\mathrm{CA}$ & 100 & 100 & 83.3 & 80 & 100 \\
\hline 12 & Amoxyclave & AMC & $\mathrm{R}$ & $\mathrm{R}$ & $\mathrm{R}$ & $\mathrm{R}$ & $\mathrm{R}$ \\
\hline
\end{tabular}

$\mathrm{n}=$ no of isolates,

Gram negative bacteria shows $>90 \%$ sensitivity to Ceftazidime, Ciprofloxacin, Lomefloxacin, Gentamicin \& Netilline. $>75 \%$ sensitivity to Pefloxacin, Ofloxacin, Cefaperazone \& Amikacin. They are resistance to Amoxyclave, Cefotaxime \& Cefuroxime.

Table 4: Antibiogram of gram-positive isolates.

\begin{tabular}{|c|c|c|c|c|}
\hline S.N & Antibiotics & $\begin{array}{c}\text { Antibiotics } \\
\text { Symbol }\end{array}$ & $\begin{array}{c}\text { Staphylococcus aureus } \\
(\mathbf{n = 1 6}) \\
\mathbf{\%}\end{array}$ & $\begin{array}{c}\text { CONS } \\
(\mathbf{n}=\mathbf{7}) \\
\mathbf{\%}\end{array}$ \\
\hline $\mathbf{1}$ & Cloxacillin & CX & 81.2 & 71.4 \\
\hline $\mathbf{2}$ & $\begin{array}{c}\text { Ampicillin } \\
+ \text { Sulbactam }\end{array}$ & AS & 75 & 71.4 \\
\hline $\mathbf{3}$ & Cefotaxime & CE & 75 & 85.7 \\
\hline
\end{tabular}


Bacteriological Profile Of Ear Infections And Its Antibiotic Susceptibility Pattern In Tertiary .....

\begin{tabular}{|c|c|c|c|c|}
\hline $\mathbf{4}$ & Roxythromycin & AT & 75 & 57.1 \\
\hline $\mathbf{5}$ & Cefotaxime & CF & 81.2 & 85.7 \\
\hline $\mathbf{6}$ & Ciprofloxacin & RC & 56.2 & 85.7 \\
\hline $\mathbf{7}$ & Tetracycline & TE & 87.5 & 100 \\
\hline $\mathbf{8}$ & Linezolid & LZ & 93.7 & 100 \\
\hline $\mathbf{9}$ & Cephalexin & PR & 93.7 & 100 \\
\hline $\mathbf{1 0}$ & Co-trimoxazole & BA & 87.5 & 85.7 \\
\hline $\mathbf{1 1}$ & Gentamicin & G & 93.7 & 100 \\
\hline $\mathbf{1 2}$ & Lincomycin & LM & 93.7 & 100 \\
\hline $\mathbf{1 3}$ & Amoxyclave & AMC & 81.2 & \\
\hline
\end{tabular}

$\mathrm{n}=$ no of isolates,

Gram positive bacteria shows $>90 \%$ sensitivity to Cephalexin, Linezolid, Gentamicin \& Tetracycline.

$>80 \%$ sensitivity Cloxacillin, Cefotaxime, Lincomycin, Co-trimoxazole, Tetracycline \& Amoxyclave.

\section{Discussion}

An ear infection (Otitis Media) refers to an infection of the middle part of the ear that lies behind the eardrum. Ear infections can occur in any age but common in babies and young children, especially those aged six to 18 months. Most children will have an ear infection before the age of five. ${ }^{[1]}$ Chronic Suppurative Otitis Media (CSOM) is chronic inflammation of middle ear, which affects the tympanic membrane, middle ear mucosa and other middle ear structures. ${ }^{[2]}$

In our study group maximum numbers of cases were from the male group 42 cases $(52.5 \%)$ and females were $38(47.4 \%)$. Humera Rashid et al shows 54\% male and $46 \%$ females were found infected by P. aeruginosa. ${ }^{[7]}$ In our study maximum number of infection was from the age group 21 to 30 years 22 cases (27.5\%). The ear infection rate in our study is similar to that of Raakhee T et al. 2014, which shows majority of the patients who had ear discharge was between 16-25 years. This was followed by the age group between 6-15 years but their study shows that females were most commonly affected than males. Pseudomonas showed high sensitivity to Ciprofloxacin (92.3\%), Gentamicin (84.61\%), Imipenem (84.61\%), Piperacillin (88.46\%). Staphylococcus aureus was sensitive to Gentamicin (90.47\%), Ciprofloxacin (90.47\%), Clindamycin (85.7\%), Caphalexin $(85.7 \%)$ and Ofloxacin $(71.42 \%) .{ }^{[8]}$ This is similar to our antibiogram showing $>90 \%$ sensitivity to Ceftazidime, Ciprofloxacin, Lomefloxacin, Gentamicin \& Netilline for GNB \& >90\% sensitivity to Linezolid, Gentamicin \& Tetracycline for GPC. Iqbal et al examined 200 ear swabs the bacterial isolates were P.aeruginosa $41.5 \%$ staphylococcus 19\%, Proteus mirabilis 18\%, Klebsiella pneumonia 10.5\%, E.coli $4 \%$ \& Beta-hemolytic streptococcus $5 \% .{ }^{[9]}$ In another study, Gul et al found that the frequency of P.aeruginosa in chronic suppurative Otitis media was $52.2 \%$, S. aureus $15 \%$, Proteus species $6.5 \%$ and Klebsiella species $2.6 \% \cdot{ }^{[10]}$ Humera Rashid et al shows $54 \%$ male and $46 \%$ females were found infected by P. aeruginosa. ceftazidime is $100 \%$, amikacin $78.3 \%$, gentamicin $81 \%$, cefipime $91.89 \%$, aztreonam $94.5 \%$ and ciprofloxacin $78.3 \%$ sensitive, these studies shows close similarity in sensitivity pattern. ${ }^{[7]} \mathbf{R}$ Shyamala et al revealed that otitis media was found to be more common in males (57\%) than in females (43\%). The bacteriologic study of otitis media revealed the isolation of a variety of organisms. Pseudomonas aeruginosa is the most prominent organism being isolated in 40 (40\%) of the cases followed Staphylococcus aureus in 31 (31\%) cases, E.coli is 21 (21\%) cases, Proteus mirabilis in 5 cases $(5 \%)$ \& Klebsiella pneumonia in 5 cases $(5 \%)$. As regards the antibiotic sensitivity Amoxiclav, Amikacin, Gentamycin \& Erythromycin has proved to be the most effective drug for aerobes. ${ }^{[11]}$ These results support our study with slight difference in sensitivity pattern however different workers showed different sensitivity patterns.

\section{Conclusion}

There can be a variation in the organisms infecting and their susceptibility pattern in ear infection. In our study Pseudomonas, Proteus, Acinetobacter, Staphylococcus aureus, CONS and Candida species were the most important organisms associated with ear infection. For Gram negative bacteria Ceftazidime, Ciprofloxacin, Lomefloxacin, Gentamicin \& Netilline appear to be the first line antibiotic to treat CSOM. Similarly, for Gram positive bacteria Cephalexin, Linezolid, Gentamicin \& Tetracycline appear to be the first line antibiotic to treat CSOM. The patients should also be advised to take the drugs for the complete prescribed duration without 
stopping in the middle. This will not only help in minimizing the complications, but also help in preventing the emergence of resistant strains. The antibiotic susceptibility patterns must be continuously and periodically evaluated to decrease the risk of resistant strains. Continuous and periodic evaluation of microbial pattern and antibiotic sensitivity of CSOM helps to decrease the potential risk of complications.

\section{Acknowledgements}

The help of Dr. A D Urhekar HOD \& Professor of Microbiology at the MGM College of Medical Sciences in the planning aspects of the study is gratefully acknowledged.

\section{References}

[1]. Richard. E. B and Roberts. M. K. (1996). Otitis Media and its complications in Nelson's Texbook of peadiatrics. pp 1814-1824

[2]. B Iqbal J, Khan W, Raza SN, Naqvi NU, Rahat ZM, Azeem QE. Frequency of chronic suppurative otitis media in the junior ranks of Pak army. Pak Armed Forces Med J 2009; 59:367-70.

[3]. Krišto B, Buljan M. Microbiology of the chronic suppurative otitis media. Medicinski Glasnik. 2011;8:2.

[4]. Srivastava A, Singh R, Varshney S, Gupta P, Bist S, Bhagat S, et al. Microbiological Evaluation of an Active Tubotympanic Type of Chronic Suppurative Otitis Media. Nepalese Journal of ENT Head and Neck Surgery. 2011;12:14-6.

[5]. Haraldsson G, Holbrook WP, Könönen E. Clonal similarity of salivary and nasopharyngeal Fusobacterium nucleatum in infants with acute otitis media experience. Journal of medical microbiology. 2004;532:161-5.

[6]. Oguntibeju O. Bacterial isolates from patients with ear infection. Indian Journal of Medical Microbiology. 2003; 214:294.

[7]. Humera Rashid, Mubarak Zeb et al. Frequency and Antimicrobial Susceptibility Pattern of Pseudomonas aeruginosa in Ear Swabs. World Applied Sciences Journal 30 (7): 812-817, 2014.

[8]. Raakhee T, Sreenivasa Rao Unguturu. Bacteriological study of discharging ear in patients attending a tertiary care hospital. Int J Res Med Sci. 2014 May;2(2):602-606

[9]. Iqbal, S. M., I.H. Udaipurwala, A. Hasan, M. Shafiq and S. Mughal, 2006. Chronic Suppurative Otitis media: disease pattern and drug sensitivity. Journal of Surgery Pakistan 11(1): 17-9.

[10]. Gul, A. A., L. Ali, E. Rahim and S. Ahmed, 2007. Chronic Suppurating Otitis media; frequency of pseudomonas aeruginosa in patients and sensitivity to various antibiotics. Professional Medical Journal 14(3): 411-5.

[11]. R Shyamala and P Sreenivasulu Reddy. The study of bacteriological agents of chronic suppurative Otitis media - Aerobic culture and evaluation. J. Microbiol. Biotech. Res., 2012, 2 (1):152-162 